\title{
ANALISIS FINANSIAL USAHABUDIDAYA IKAN NILA (Oreochromis niloticus) DI KARAMBA JARING TANCAP DI DESA SINUIANKECAMATAN REMBOKEN Omega V. Sambuaga ${ }^{1}$; Lexy K. Rarung ${ }^{2}$; Swenekhe S. Durand ${ }^{2}$ \\ 1) Mahasiswa Fakultas Perikanan dan IImu Kelautan Universitas Sam Ratulangi, Manado. \\ 2) Staff Pengajar Fakultas Perikanan dan IImu Kelautan Universitas Sam Ratulangi, Manado. Koresponden email: omegasambuaga@gmail.com
}

\begin{abstract}
This study aims to review knowing the state of the District Sales Manager village Sinuian Remboken And find out if the fish farming in net cages step feasible OR feasible for the review run. The basic method basis Of Research Singer Namely Studies CASE, data retrieval is done Operates census where respondents lts taken is $100 \%$ of a population of Fishermen fish of tilapia in the village Sinuian, data collected is data primary data the collected with how to observe and secondary data in the form evidence, notes OR statements of historical Yang has arranged hearts archives for review analyzing fish farming with analysis methods operating profit data such as net income, the rate of profit, benefit cost ratio, profitability, break-even point, the payback period, net present value, internal rate and returns.

Based on the analysis in the financial, fish farming in net cages step in the Village Sinuian eligible to run because the value of a positive operating profit, profit rate of fish farming reached $57.23 \%, 92.22 \%$ profitability, the value of the benefit cost ratio> 1 namely 1.57; BEP or break-even point is BEP sales of Rp. 24,562,016 and BEP 982.48kg unit further investment return rate of tilapia fish farming are 1 year 1 month, with a 92.09\% IRR, NPV 329,059,572.14.
\end{abstract}

Keywords: cage nets step, financial analysis, tilapia

\begin{abstract}
Abstrak
Penelitian ini bertujuan untuk Mengetahui keadaan umum Desa Sinuian Kecamatan Remboken dan mengetahui apakah usaha budidaya ikan di karamba jaring tancap layak atau tidak layak untuk dijalankan. Metode dasar dari penelitian ini yaitu studi kasus, pengambilan data dilakukan secara sensus dimana responden yang diambil adalah $100 \%$ dari populasi nelayan pembudidaya ikan nila di Desa Sinuian, data yang dikumpulkan adalah data primer yaitu data yang terkumpul dengan cara observasi dan data sekunder berupa bukti, catatan atau laporan historis yang telah tersusun dalam arsip untuk menganalisis usaha budidaya ikan dengan metode analisis data seperti operating profit, net profit, profit rate, benefit cost ratio, rentabilitas, break event point, payback period, net present value, dan internal rate of return.

Berdasarkan hasil analisis secara finansial, usaha budidaya ikan di karamba jaring tancap di Desa Sinuian layak untuk dijalankan karena nilai operating profit positif, profit rate dari usaha budidaya ikan ini mencapai $57,23 \%$, rentabilitas $92,22 \%$, nilai benefit cost ratio $>1$ yaitu 1,57; BEP atau titik impas yaitu BEP penjualan Rp. 24,562,016dan BEP satuan $982.48 \mathrm{~kg}$ selanjutnya tingkat pengembalian investasi dari usaha budidaya ikan nila ini adalah 1 tahun 1 bulan, dengan IRR 92,09\%, NPV 329,059,572.14.
\end{abstract}

Kata Kunci : Karamba jaring tancap, analisis finansial, ikan nila

\section{PENDAHULUAN}

Sumberdaya alam mempunyai hubungan yang sangat erat dengan pertumbuhan ekonomi yang terjadi di suatu Negara (khususnya Negara sedang berkembang), dimana semakin tinggi pertumbuhan ekonominya, akan mengakibatkan persediaan sumberdaya alam yang tersedia akan semakin berkurang. Hal ini karena pertumbuhan ekonomi yang tinggi akan selalu menuntut adanya barang sumberdaya dalam jumlah yang tinggi pula, dan barang sumberdaya ini diambil dari persediaan sumberdaya alam yang ada. Dengan demikian, terdapat hubungan 
yang positif antara jumlah barang sumberdaya dengan pertumbuhan ekonomi, disamping juga hubungan yang negatif antara persediaan sumberdaya alam dengan pertumbuhan ekonomi (Anhar, 2012).

Di dalam dunia usaha perikanan dikenal 3 jenis bidang usaha, yaitu usaha perikanan tangkap, usaha perikanan budidaya atau akuakultur serta usaha perikanan pengolahan. Usaha perikanan tangkap adalah sebuah kegiatan usaha yang berfokus untuk memproduksi ikan dengan cara menangkap ikan, sedangkan definisi usaha perikanan pengolahan adalah sebuah kegiatan usaha yang bertujuan untuk meningkatkan nilai tambah yang dimiliki oleh sebuah produk perikanan, dan usaha perikanan budidaya adalah sebuah kegiatan usaha yang bertujuan untuk memproduksi ikan dalam sebuah wadah pemeliharaan yang terkontrol.

Budidaya ikan merupakan salah satu komponen yang penting pada sektor perikanan.Hal ini berkaitan dengan perannya dalam menunjang ketersediaan pangan nasional, menciptakan pendapatan dan lapangan kerja.Budidaya ikan juga berperan dalam mengurangi beban sumber daya laut.Di samping itu budidaya ikan dianggap sebagai sektor penting untuk mendukung perkembangan ekonomi pedesaan (Anonimous, 2014). Salah satu jenis usaha budidaya perikanan adalah dengan menggunakan media karamba jaring tancap.Karamba jaring tancap merupakan jaring kantong berbentuk persegi yang dipasang pada kerangka bambu atau kayu yang ditancap pada dasar perairan.

Salah satu danau di Sulawesi Utara yang terletak di Kabupaten Minahasa menjadi tempat usaha budidaya ikan air tawar dengan menggunakan media karamba jaring tancap, Danau Tondano adalah danau yang terletak di daerah kabupaten Minahasa Induk dan merupakan danau terluas di Sulawesi Utara dengan luas $5600 \mathrm{Ha}$ dan terletak diatas ketinggian 650 meter diatas permukaan laut (Wahyuningsih, 2013).

\section{Rumusan Masalah}

Usaha budidaya ikan dengan media karamba jaring tancap di Desa Sinuian sudah berjalan cukup lama dan diharapkan dapat berkembang menjadi lebih besar yang akhirnya mampu meningkatkan kesejahteraan pembudidaya, sehingga dapat dirumuskan masalah bagaimana kelayakan usaha budidaya ikan nila di karamba jaring tancap secara finansial, untuk itu perlu dilakukan analisis secara finansial usaha budidaya ikan nila di karamba jaring tancap di Desa Sinuian Kecamatan Remboken.

\section{Tujuan Penelitian}

1. Mengetahui keadaan umum Desa Sinuian Kecamatan Remboken.

2. Mengetahui apakah usaha budidaya ikan di karamba jaring tancap layak atau tidak layak untuk dijalankan. 


\section{Tempat Penelitian}

Penelitian ini dilakukan di daerah

Danau Tondano, khususnya kepada masyarakat Desa Sinuian Kecamatan Remboken yang memiliki usaha budidaya ikan nila di karamba jaring tancap.

\section{Waktu Penelitian}

Waktu yang diperlukan dalam pelaksanaan penelitian mulai dari survey lokasi, konsultasi, penyusunan rencana kerja penelitian, pelaksanaan penelitian, pengolahan data dan analisis data dan sampai pada ujian \pm 6 bulan.

\section{METODOLOGI PENELITIAN}

Metode dasar yang digunakan dalam penelitian ini adalah studi kasus. Kasus yang diteliti adalah usaha karamba jaring tancap (KJT) yang dijalankan oleh pembudidaya ikan di Desa Sinuian Kecamatan Remboken. Pengambilan data dilakukan dengan menggunakan metode sensus, hal mana responden yang diambil adalah 100\% dari populasi petani ikan yang ada di Desa Sinuian kecamatan Remboken.Data yang dikumpulkan adalah data primer dan data sekunder.

Semua data yang dikumpulkan selanjutnya dianalisis secara deskriptif kualitatif dan deskriptif kuantitatif. Untuk mengetahui tingkat kelayakan usaha budidaya ikan di karamba jaring tancap, penulis menggunakan analisis finansial seperti operating profit, net profit, profit rate, benefit cost ratio, rentabilitas dan break event point, payback period, internal rate of return, net present value.
HASIL DAN PEMBAHASAN

Faktor-Faktor Produksi Usaha Budidaya Ikan di Karamba Jaring Tancap

\section{Benih}

Benih yang ditebarkan diperoleh dari desa tumaluntung dengan harga $\mathrm{Rp}$. 750/ekor. Benih yang dibeli berukuran 6 - $8 \mathrm{~cm}$, ditebarkan pada karamba jaring tancap berukuran $5 \times 8 \mathrm{~m}$. Dalam satu periode benih yang ditebarkan berkisar antara 7.000 - 25.000, dari begitu banyak benih yang ditebarkan petani ikan akan memanen ikan berkisar antara $1.200-4.500 \mathrm{~kg}$ ikan nila dalam satu periode.

\section{Pemeliharaan}

Pemeliharaan ikan nila oleh pembudidaya ikan di Desa Sinuian berkisar antara 3-4 bulan, jadi dalam 1 tahun ikan akan dipanen sebanyak 3 kali. Tapi kadang kala sudah dipanen sebelum waktunya, artinya sebelum ikan memasuki ukuran panen para pembudiaya akan memanen ikan dengan alasan permintaan pembeli dan atau pasar.

\section{Pakan}

Pakan yang diberikan kepada benih ikan berukuran $6-8 \mathrm{~cm}$ adalah pelet halus jenis 781-1 dengan harga $9.000 / \mathrm{kg}$, sedangkan pakan yang diberikan pada ikan nila di karamba jaring tancap Desa Sinuian adalah pelet jenis charoen phokpand (CP) yang dibeli dari Kota Tomohon dengan harga Rp. 435.000/karung dengan berat $50 \mathrm{~kg} / \mathrm{karung}$. Pakan diberikan 2 kali dalam sehari yaitu pada pagi hari pukul 08.00 dan pada siang hari pukul 14.00 . 


\section{Pemasaran}

Proses pemasaran ikan nila di Desa Sinuian sangat sederhana, ikan yang dipanen oleh pembudidaya akan dibeli oleh pembeli yang datang langsung ke lokasi budidaya ikan, pembeli yang datang berasal dari Eris dan Watumea. Pembudidaya ikan nila di Desa Sinuian sangat jarang untuk menjual ikan hasil panen ke pasar terdekat karena harga yang ditawarkan dipasar sangat rendah.

\section{Tenaga Kerja}

Dalam usaha karamba jaring tancap di Desa Sinuian juga memiliki tenaga kerja yang membantu pemilik usaha menjalankan budidaya ikan.Tenaga kerja ini kebanyakan adalah keluarga dan tetangga pemilik usaha, walaupun keluarga tetap saja diberikan upah atau gaji sekitar Rp. 1.000.000 sampai dengan Rp. 1.500 .000 setiap bulannya.

\section{Struktur Biaya}

\begin{tabular}{|c|c|c|}
\hline \multicolumn{3}{|c|}{ INVESTASI } \\
\hline No. & Uraian & Jumlah \\
\hline 1. & Rumah Jaga & $23,500,000$ \\
\hline 2. & Karamba Jaring Tancap & $37,250,000$ \\
\hline 3. & Perahu & $1,500,000$ \\
\hline 4. & Instalasi Listrik & 900,000 \\
\hline & Jumlah Investasi & $63,150,000$ \\
\hline \multicolumn{3}{|c|}{ BIAYA TETAP } \\
\hline 1. & Rumah Jaga & $1,733,333$ \\
\hline 2. & Karamba Jaring Tancap & $8,650,000$ \\
\hline 3. & Perahu & 146,667 \\
\hline 4. & Instalasi Listrik & 31,667 \\
\hline \multicolumn{2}{|r|}{ Jumlah Biaya Tetap } & $10,561,667$ \\
\hline \multicolumn{3}{|c|}{ BIAYA TIDAK TETAP } \\
\hline 1. & Benih & $32,400,000$ \\
\hline 2. & Pakan benih & $9,540,000$ \\
\hline 3. & Pakan dewasa & $43,245,000$ \\
\hline 4. & Biaya listrik & 195,000 \\
\hline 5. & Tenaga Kerja & $5,820,000$ \\
\hline \multicolumn{2}{|r|}{ Jumlah Biaya Tidak Tetap } & $91,200,000$ \\
\hline
\end{tabular}

\section{Pendapatan}

Setiap orang yang menjalankan suatu usaha pasti menginginkan pendapatan yang lebih atau keuntungan yang besar dari usaha yang dijalankan.Pendapatan juga merupakan salah satu faktor untuk melihat berapa besar tingkat kesejahteraan seseorang atau keluarga (Yennie, 1999).
Pendapatan pembudidaya ikan nila tergantung dari berapa kilogram ikan yang dipanen dalam satu periode, harga jual ikan nila, dan biaya yang dikeluarkan selama proses budidaya.

\begin{tabular}{|c|c|c|}
\hline No. & Periode & $\begin{array}{c}\text { Pendapatan } \\
\text { (Rp.) }\end{array}$ \\
\hline 1. & $\mathrm{I}$ & 61.000 .000 \\
\hline 2. & $\mathrm{II}$ & 41.500 .000 \\
\hline 3. & III & 57.500 .000 \\
\hline \multicolumn{2}{|c|}{ Total Pendapatan per Tahun } & 160.000 .000 \\
\hline
\end{tabular}


Berdasarkan struktur biaya dan pendapatan maka dapat dibuat analisis finansial sebagai berikut :

$\begin{array}{ll}\text { Investasi (I) } & =63.150 .000 \\ \text { Biaya tetap (FC) } & =10.561 .667 \\ \text { Biaya tidak tetap (VC) } & =91.200 .000 \\ \text { Biaya total (TC) } & =10.761 .667 \\ \text { Total penerimaan (TR) } & =160.000 .000\end{array}$

Dalam analisis finansial menggunakan rumus :

\section{Operating Profit}

$$
\begin{aligned}
& \mathrm{OP}=\mathrm{TR}-\mathrm{VC} \\
& =160.000 .000-91.200 .000 \\
& =\text { Rp. } 68.800 .000
\end{aligned}
$$

Operating profit dari usaha ini sebesar Rp. 68.800.000 adalah keuntungan yang diperoleh yang merupakan selisih antara seluruh pendapatan kotor dikurangi dengan biaya tidak tetap dan dapat digunakan untuk biaya produksi berikutnya.

\section{Net Profit \\ $\Pi=\mathrm{TR}-\mathrm{TC}$ \\ - $160.000 .000-101.761 .667$ \\ $=$ Rp. 58.238 .333}

Net profit atau keuntungan absolut sebesar Rp.58.238.333. hasil ini menunjukkan bahwa usaha budidaya ikan di Desa Sinuian dapat dijamin keberlangsungannya karena keuntungan bersifat positif.

\section{Profit Rate}

$$
\frac{\pi}{T C} \times 100 \%=\frac{58.238 .333}{101.761 .667} \times 100 \%=57,23 \%
$$

Profit rate yang didapatkan adalah $57,23 \%$. Tingkat keuntungan usaha ini menunjukkan bahwa usaha ini cukup mengguntungkan.

\section{Rentabilitas}

$$
\frac{\pi}{i} \times 100 \%-\frac{58.238 .333}{63.150 .000} \times 100 \%-92,22 \%
$$

Rentabilitas merupakan ratio keuntungan bersih dengan investasi satu unit usaha. Hasil analisis menunjukkan besarnya rentabilitas pada usaha budidaya ikan nila adalah sebesar $92,22 \%$.

\section{Benefit Cost Ratio}

$$
B C R=\frac{T R}{T C}=\frac{160.000 .000}{101.761 .667}=1,57
$$

Nilai BCR untuk usaha usaha budidaya di karamba jaring tancap di Desa Sinuian lebih dari satu yaitu 1,57 . Apabila nilai BCR lebih dari satu maka usaha ini layak untuk dijalankan.

\section{Break Event Point}

$$
\begin{aligned}
& \text { BEP Penjualan }=\frac{F C}{1-\left(\frac{V C}{T R}\right)}=\frac{10.561 .667}{1-\left(\frac{91.200 .000}{160.000 .000}\right)}=R p .24 .562 .016 \\
& B E P \text { Satuan }=\frac{\text { BEP Penjualan }}{\text { Harga Satuan }}=\frac{24.562 .016}{25.000}=982,48
\end{aligned}
$$

\section{Hasil analisis BEP Penjualan} menggambarkan titik impas usaha budidaya di karamba jaring tancap di Desa Sinuian pada penjualan Rp.24.562.016Nilai ini merupakan nilai acuan penjualan yang harus dicapai pengusaha budidaya untuk keuntungan nihil, artinya penjualan ikan harus lebih dari nilai BEP Penjualan.

Hasil analisis BEP Satuan menggambarkan titik impas usaha budidaya di karamba jaring tancap di Desa Sinuian pada produksi $982,48 \mathrm{~kg}$. 
Nilai ini merupakan nilai acuan produksi yang harus dicapai pengusaha budidaya untuk keuntungan nihil, artinya produksi ikan hasil budidaya harus lebih dari nilai BEP Satuan.

\section{Jangka Waktu Pengembalian Investasi}

$$
\frac{l}{\pi} \times n \text { t.h.hin }=\frac{63 \cdot 150.000}{58.238 .333} \times 1=1,08 \text { t.a.m.n. }
$$

Hasil analisis untuk jangka waktu pengembalian investasi 1,08 tahun atau 1 tahun 1 bulan.

Cash Flow Usaha Budidaya di Karamba Jaring Tancap Di Desa Sinuian

\begin{tabular}{|c|c|c|c|c|c|}
\hline Tahun & $\begin{array}{c}\text { Arus } \\
\text { Penerimaan }\end{array}$ & $\begin{array}{c}\text { Arus } \\
\text { Pengeluaran }\end{array}$ & Net Benefit & $\mathbf{1 2 \%}$ & Present Value \\
\hline 1 & $160,000,000.00$ & $101,761,666.67$ & $58,238,333.33$ & 0.8929 & $51,998,511.90$ \\
\hline 2 & $160,000,000.00$ & $101,761,666.67$ & $58,238,333.33$ & 0.7972 & $46,427,242.77$ \\
\hline 3 & $160,000,000.00$ & $101,761,666.67$ & $58,238,333.33$ & 0.7118 & $41,452,895.33$ \\
\hline 4 & $160,000,000.00$ & $101,761,666.67$ & $58,238,333.33$ & 0.6355 & $37,011,513.69$ \\
\hline 5 & $160,000,000.00$ & $101,761,666.67$ & $58,238,333.33$ & 0.5674 & $33,045,994.37$ \\
\hline 6 & $160,000,000.00$ & $101,761,666.67$ & $58,238,333.33$ & 0.5066 & $29,505,352.11$ \\
\hline 7 & $160,000,000.00$ & $101,761,666.67$ & $58,238,333.33$ & 0.4523 & $26,344,064.39$ \\
\hline 8 & $160,000,000.00$ & $101,761,666.67$ & $58,238,333.33$ & 0.4039 & $23,521,486.06$ \\
\hline 9 & $160,000,000.00$ & $101,761,666.67$ & $58,238,333.33$ & 0.3606 & $21,001,326.84$ \\
\hline 10 & $160,000,000.00$ & $101,761,666.67$ & $58,238,333.33$ & 0.3220 & $18,751,184.68$ \\
\hline \multicolumn{7}{|c|}{} & & NPV & $329,059,572.14$ \\
\cline { 1 - 3 } & \multicolumn{7}{|c|}{} & &
\end{tabular}

\begin{tabular}{|l|r|}
\hline NPV & $329,059,572.14$ \\
\hline IRR & $92.09 \%$ \\
\hline BC RATIO & 1.57 \\
\hline
\end{tabular}

Nilai NPV pada usaha budidaya di karamba jaring tancap di Desa Sinuian bernilai positif $(329,059,572.14)$, sedangkan nilai IRR lebih besar dari bunga bank (12\%) menyatakan usaha budidaya layak dilaksanakan.

\section{KESIMPULAN DAN SARAN Kesimpulan}

1. Berdasarkan hasil analisis secara finansial, nilai operating profit positif, profit rate dari usaha budidaya ikan ini mencapai $57,23 \%$, rentabilitas $92,22 \%$, nilai benefit cost ratio $>1$ yaitu 1,57; BEP atau titik impas yaitu BEP penjualan Rp. 24,562,016 dan BEP satuan $982.48 \mathrm{~kg}$ selanjutnya tingkat pengembalian investasi dari usaha budidaya ikan nila ini adalah 1 tahun 1 bulan, dengan IRR 92,09\%, NPV 329,059,572.14

2. Usaha budidaya ikan nila dengan media karamba jaring tancap di Desa Sinuian Kecamatan Remboken layak untuk dijalankan, berdasarkan hasil analisis usaha ini dapat mengembalikan modal dalam waktu 1 tahun 1 bulan. 


\section{Saran}

Nelayan pembudidaya ikan nila di Karamba Jaring Tancap yang ada di Desa Sinuian Kecamatan Remboken sebaiknya lebih memperhatikan jaring dan karamba yang digunakan karena masih banyak karamba yang tidak memiliki jaring sehingga tidak dapat digunakan untuk menebarkan benih, karena jika pembudidaya memanfaatkan karamba yang ada pendapatan yang diperoleh akan lebih besar.

\section{DAFTAR PUSTAKA}

Anonimous, 2014, Perbedaan pertumbuhan ikan bawal air tawar (Colossoma macropomum) akibat pemberian pakan alami, pakan buatan serta kombinasinya.Departemen Biologi FMIPA USU.

Anhar, F., 2012. Pengolahan Sumberdaya Ikan Indonesia. Universitas Syiah Kuala Banda Aceh.

Wahyuningsih, Y. 2013. Indentifikasi Budidaya ikan mas dan ikan Nila dalam karamba jaring apung ganda secara intensif di danau Tondano. Universitas Diponegoro.

Yennie, R. 1999. Skripsi Analisis Finansial Usaha Budidaya Ikan Kerapu di Kelurahan Paudean Kecamatan Bitung Selatan Kotamadya Bitung.Manado FPIK UNSRAT. 
